\title{
Municipal Temperature and Heatwave Predictions as a Tool for Integrated Socio-Environmental Impact Analysis in Brazil
}

\author{
D. Costa1,2*, S. Hacon², A. S. P. Siqueira², S. L. L. A. Pinheiro², K. S. Gonçalves², A. Oliveira², \\ P. $\operatorname{Cox}^{1}$ \\ ${ }^{1}$ College of Engineering, Mathematics and Physical Sciences, University of Exeter, Exeter, UK \\ ${ }^{2}$ National School of Public Health/Oswaldo Cruz Foundation (FIOCRUZ)/ENSP, Rio de Janeiro, Brazil \\ Email: ${ }^{*}$ d.costa@exeter.ac.uk
}

Received 6 June 2015; accepted 15 September 2015; published 18 September 2015

Copyright (C) 2015 by authors and Scientific Research Publishing Inc.

This work is licensed under the Creative Commons Attribution International License (CC BY).

http://creativecommons.org/licenses/by/4.0/

C) (i) Open Access

\begin{abstract}
Numerical climate models render data in a gridded format which is often problematic for integrated analysis with other kinds of data in jurisdictional formats. In this paper a joint analysis of municipal Gross Domestic Product per capita (GDPc) and predicted temperature increase was undertaken in order to estimate different levels of human and economic exposure. This is based on a method of converting model outputs into a country municipal grid which enabled depicting climate predictions from the Eta-Hadgem2-ES Regional Climate Model (RCM) into the municipal level in Brazil. The conversion to country municipality grid was made using a combination of interpolation and buffering techniques in ArcGIS for two emission scenarios (RCP 4.5 and 8.5) and three timeframes (2011-2040, 2041-2070, 2071-2100) for mean temperature increase and number of heatwave days (WSDI). The results were used to support the Third National Communication (TCN) of Brazil to the United Nations Framework Convention on Climate Change (UNFCCC) and show a coherent matching of the gridded output from the original RCM. The joint climate and GDPc analysis show that in the beginning of the century the more severe warming is centred over regions where GDPc is generally higher (Centre-West and Southeast). At the end of the century, critical levels of warming spread north and northeastwards where municipalities have the lowest GDPc levels. In the high emission scenario (RCP 8.5), the strongest warming and the spreading over poorer regions are anticipated to the mid-century. These results are the key to further explore solutions for climate change adaptation based on current resources and prepare in different sectors, for long-term risk management and climate adaptation planning strategies.
\end{abstract}

\footnotetext{
${ }^{*}$ Corresponding author.
} 


\section{Keywords}

\section{Climate Change, Municipality, Integrated Analysis, Spatial Interpolation, Climate Impacts, Socio-Environmental Impact Analysis}

\section{Introduction}

In the prospect of a changing and more extreme climate, different sectors in society have an increasing demand for Climate Services [1] including multi-scenario climate projections for climate change impact and risk assessments. In the context of Brazil, in the last 7 years a series of national and sectorial climate change policy documents have been developed, generating an unprecedented demand for climate information to support the National Policy on Climate Change, the National Adaptation Plan and the socioeconomic study Brazil $20^{\circ} 40^{\circ}$.

Climate changes globally, and impacts and vulnerabilities are felt and expressed locally (IPCC WG II), needing high-resolution predictions beyond the current best resolutions of Global Climate Models (GCMs) to better indicate local and regional changes in climate patterns and extremes.

To overcome resolution limitations in GCMs, dynamical downscaling is often undertaken through nesting regional climate models (RCMs) within GCMs enabling greater resolution for climate impact and risk assessment [2].

The Eta RCM has been developed by the Brazilian CPTEC/INPE and has been operational for weather forecasting since 1997. In recent years it has also been considered sufficiently robust for dynamical downscaling [3] and regional climate change studies [4]. The latest advancement in the Eta RCM is its $20 \mathrm{~km}$ resolution where, nested within two CMIP5 models (Hadgem2-ES and MIROC5) and the Brazilian Earth System Model (BESM). This allows for the first time to build a Poor Man's ${ }^{2}$ multi-GCM ensemble which enabled a first evaluation and model intercomparison of Eta's regional climate simulations [5].

Despite the higher-resolution of RCMs and the good capabilities of the Eta model in simulating South American climate features, the gridded format in which the data are delivered is difficult and often incompatible with other social and economic spatial data. This is problematic for assessing the implications and risks of climate change to different sectors, as impacts and planning for climate adaptation require a combined analysis of environmental pressures and socio-ecological resilience [6]. Without a compatible jurisdictional format, such analysis becomes inviable in most cases. Therefore, it is necessary to define a conversion methodology to interpolate model gridded outputs into a jurisdictional scale (municipality, state, country, etc.) ensuring that the spatial patterns and outputs from the original model are not substantially altered. With this latest $20 \mathrm{~km}$ resolution, it is now reasonable to conceive a municipalisation of climate simulations to accurately translate gridded climate model predictions into meaningful jurisdictional climate change data.

This paper presents a methodology used to interpolate the gridded outputs from the Eta RCM into the Brazilian municipality network so as to enable an integrated analysis of climate, health and socioeconomic data to inform the Health Chapter of the Third National Communication (TCN) of Brazil to the UNFCCC. The municipality scale was chosen as a best common ground for integrated analysis combining climate model outputs, socioeconomic census data and data from the Brazilian Universal Health System (SUS) health database (DATASUS).

The municipal level also allows for an intra-state scale of spatial analysis which is the key to inform state health surveillance policies under climate change [7]. Learning from a science-policy interface experience was crucial to be informed about which jurisdictional level would deliver best analytical potential for policy planning and making in Brazil. This realisation draws from the experience with Brazilian health and environment stakeholders from lessons under the PULSE-Brazil project [8]. The municipal scale was pinpointed as the best spatial scale to analyze climate predictions allowing a comparison with socioeconomic and health data and having a climate change resolution at a sub-state level for the whole of Brazil. The methodology was also developed permitting straightforward replicability for future scenarios and model runs, as well as for different geographical contexts beyond Brazil.

${ }^{1}$ An initiative led by the Secretary of Strategic Affairs from the Brazilian President's Office focused on the social and economic implications of Climate Change impacts and Adaptation in Brazil until 2040.

${ }^{2}$ Ensemble made of at least three different climate models. 
The results from this municipalisation enabled the construction of a national database of climate projections in two emission scenarios (RCP 4.5 and 8.5) along three time periods until 2100, and for the 5565 Brazilian municipalities. The database was used to undertake two integrated analysis of climate change: 1 ) vulnerability due to socioeconomic and/or healthcare accessibility reasons [9] and 2) risk and impact [10].

The Material and Methods section identifies the climate variables and analysis chosen to evaluate levels of future change as well as details on the spatial municipalisation technique applied. The Results section shows the maps resulting from the municipal climate outputs in two global emission scenarios: firstly for mean annual temperature change and secondly for heatwave days. In the Discussion section, the results for the latter are discussed more extensively. In order to illustrate this methodology, an example application is presented associating the results from the municipal climate projections and current municipal GDP per capita (GDPc), allowing for an analysis of socioeconomic exposure to mean temperature increase. Finally, the conclusions reflect upon the relevance of this methodology and data to generate useful information to support climate adaptation decisionmaking.

\section{Material and Methods}

\subsection{Difference to Present $(\delta T)$}

\section{Temperature}

The climate regional predictions used were from outputs of the Eta model nested to the UK HadGEM2-ES for two global emission scenarios: RCP 4.5 and 8.5 [5]. The data was divided into three future time frames of 30 years: 2011-2040; 2041-2070; 2071-2100, and one present baseline period; 1961-1990.

In order to estimate the level of future change on mean annual temperature for each municipality in Brazil, the difference $(\delta T)$ between future mean temperature $(T f)$ in each time frame in each scenario and the average temperature in the baseline $(T b)$ period was calculated.

$$
\delta T=T f-T b
$$

\subsection{Extreme Temperature Events-Heatwaves (WSDI)}

Equation (1) was also used to calculate the level of change of a heatwave indicator. There are different heatwave definitions and metrics for multiple type of impact analysis where different methodologies are designed to identify impacts from heatwave events in climate time series in contrasting regional and sectorial contexts [11]-[13] as well as globally [14] [15].

One relevant aspect in designing heatwave metrics for human health impact studies is acclimatization. Human health impacts from heatwaves can vary depending on the capacity of different groups to thermoregulate, i.e. for their own individual bodies to acclimatise and adjust to heat. For this reason, it is very important to take into account recent previous temperatures [12] when assessing the impact of hot periods. Most heatwave metrics that have been applied in the context of a human health impact analysis use recent or past climate data and only a few use future predictions. That is the case for [13] who used an ensemble of RCMs to predict changes in heatwave features in Europe. However, estimations with the indices developed by [11] have not yet been applied to future predictions of climate under different global warming and/or land-use scenarios.

In this paper, we used the Warm Spell Duration Index (WSDI), a widely used heatwave index [14] [16]. This metric was developed by the World Meteorological Organization (WMO) Commission for Climatology (CCl)/ Climate Variability and Predictability (CLIVAR)/Joint Technical Commission for Oceanography and Marine Meteorology (JCOMM) Expert Team on Climate Change Detection and Indices (ETCCDI) [17]. The WSDI index expresses the number of days per year when maximum temperatures above the 90th percentile (Tx90th) occur for a period of 5 or more consecutive days [18]. The WSDI accounts for the existence of a thermal threshold adjusted or acclimatised to each grid point where it is calculated, for frequency (number of days in heatwave per year) and also considers the requirement for consecutiveness of excess heat days. However, it is unable to provide detail on heatwave features such as heatwave duration and intensity (as for instance [18], which is of relevance for sectorial impacts, such as public health). Nevertheless, the WSDI provided for some acclimatisation features where the Tx90th percentile is calculated taking into account the temperature time series from each grid point. This means that for instance in normally hot regions, the threshold for a heatwave would be higher than in a location with a cooler climate. This is different from the indicators used by [18] where the temperature thresh- 
old was prescribed for the whole geographical domain.

The WSDI $\delta T$ is the difference between the average number of heatwaves in future timeframes and the baseline timeframe in the $20^{\text {th }}$ century. The human health impact analysis from the results presented in this paper are explained and discussed in [18].

\subsection{Municipalization of Climate Gridded Data}

The $\delta T$ results calculated at a grid point scale were then imported into ArcMap software (ArcGIS) in a raster format and were converted into point data with the same resolution of the Eta model of approximately $20 \mathrm{~km}$ (Figure 1).

The climate data for each municipality was calculated as the mean of each of the model grid-point values contained within each municipal jurisdiction.

Some municipalities were too small to have information from at least one point. To overcome this, a buffer with a $10 \mathrm{~km}$ Euclidean distance was created around each grid point expanding its domain and thereby covering the space without data in between each point (10 km buffer around each point covers the $20 \mathrm{kms}$ in between each of them). Figure 1 shows the spatial coverage of the buffer, the detail of the Euclidean distance and Figure 2 shows the result without applying the buffer.

An example of the final application of the municipalisation technique explained here using a buffering technique is shown in Figure 3 comparing an original raster model dataset to the municipalised version of it.

\section{Results}

\subsection{Increase in Future Average Mean Temperature $(\delta T)$}

The $\delta T$ results show a progressive warming trend through the 21st century. Warming is centred on the continental interior of the country, namely the Centre-West region spreading across to the interior of the South and Southeast regions. As time progresses into the $21^{\text {st }}$ century, warming expands southeastwards and northwards into the Amazon region and further into the Southeast of Brazil.

There is a clear warming gradient from coastal regions into the interior of the continent showing the enhanced differential warming effect of land over sea in the country, where coastal municipalities warm less than landlocked
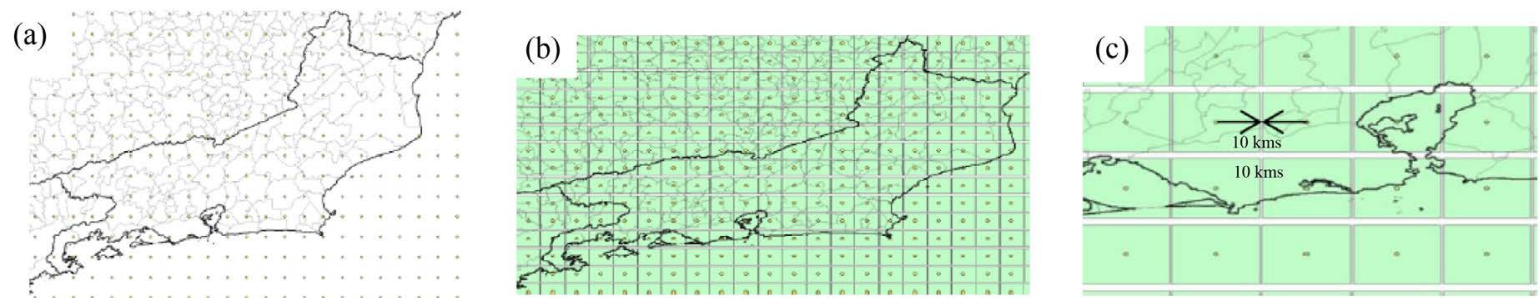

Figure 1. Grid points from the Eta-HadGEM2-ES (a) in a $20 \mathrm{~km}$ resolution over the state of Rio de Janeiro and the results from a buffering application to each point (b) with a $10 \mathrm{~km}$ Euclidean distance (c).
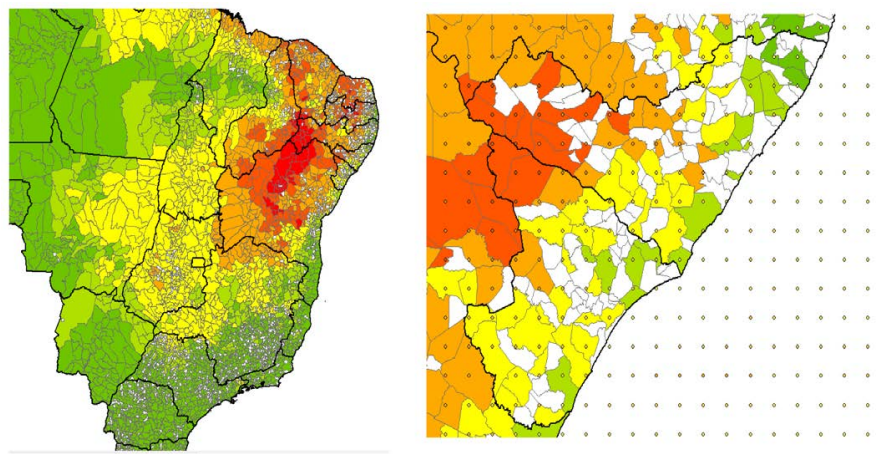

Figure 2. Results of the first spatial interpolation, before applying the buffering technique. In total, 1684 municipalities in Brazil did not get at least one point of data due to being too small. 
ones (Figure 4).

By mid-century, even under the RCP 4.5 scenario, virtually the whole country has surpassed the threshold of $2^{\circ} \mathrm{C}$ warming and the Centre-West region even exceeds $4^{\circ} \mathrm{C}$ (Figure 5). This indicates that Brazil is likely to warm more than the world average (Figure 7).

At the end of the century a greater difference between the scenarios emerges. In the RCP 4.5 most of the country warms above $2^{\circ} \mathrm{C}$ whilst in the RCP 8.5 temperature increase goes over $4^{\circ} \mathrm{C}$ for nearly the entire country. Despite this difference, both show the same patterns of warming, where higher warming is observed in the Centre-West and Southeast regions and over central Amazon around the Metropolitan region of Manaus (Figure 6).

Table 1 summarizes the warming trends of both scenarios across Brazilian municipalities, comparing with the average warming from the CMIP5 multi-model ensemble with the lowest, mean and highest municipal warming from the results from the municipal results for Brazil.

\subsection{Temperature Extremes-Heatwaves (WSDI)}

The WSDI $\delta T$ results from the model outputs in Figure 7 reveal a spatially diverse and scenario dependent
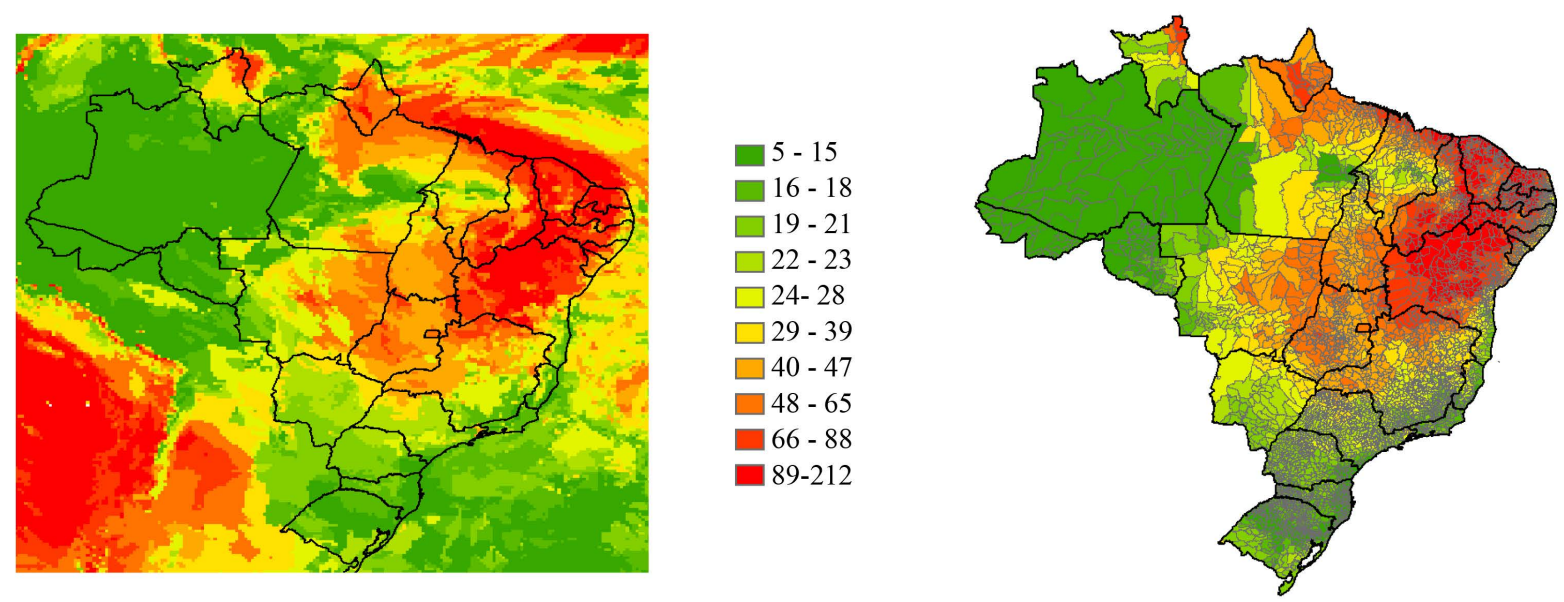

Figure 3. Comparison between the original model output (left) and the final spatial interpolation results (right). The two maps had data classified with the same class range represented in the scale legend in the centre. The data used as test is the CDD indicator showing values for 1961.
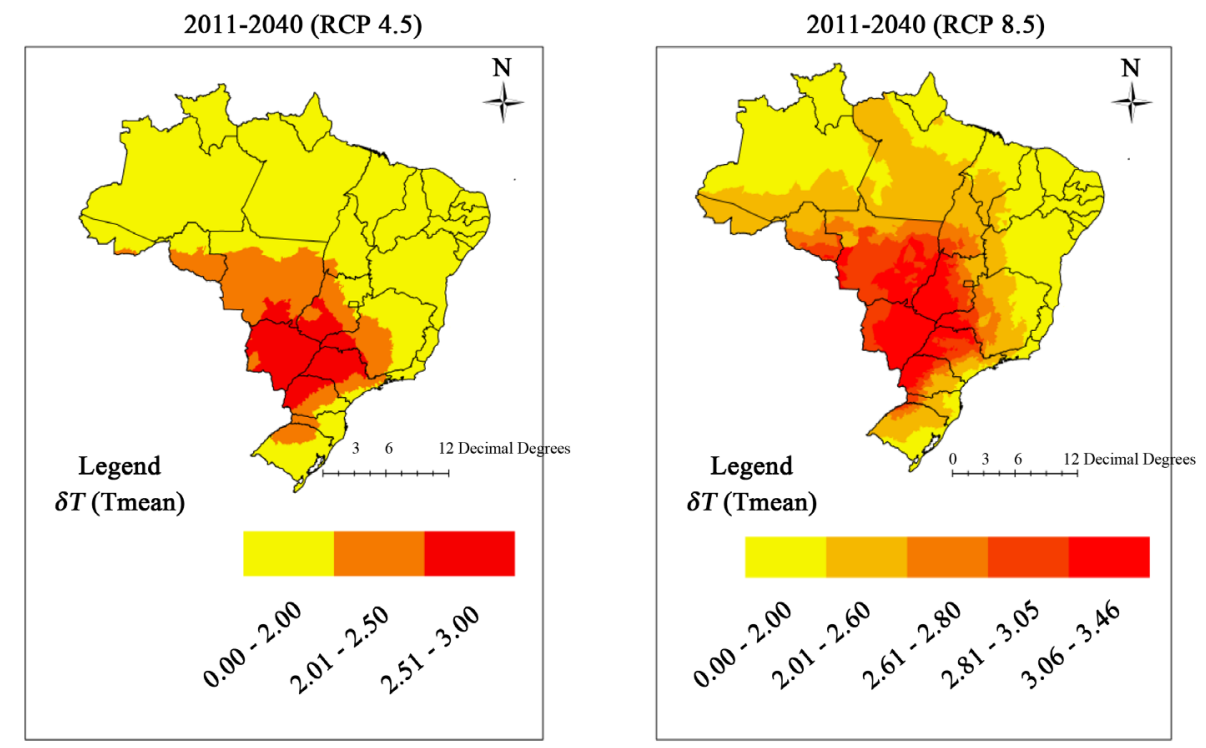

Figure 4. Municipalization of $\delta T\left({ }^{\circ} \mathrm{C}\right)$ in the first time frame (2011-2040) for RCP 4.5 (left) and 8.5 (right) scenarios. 

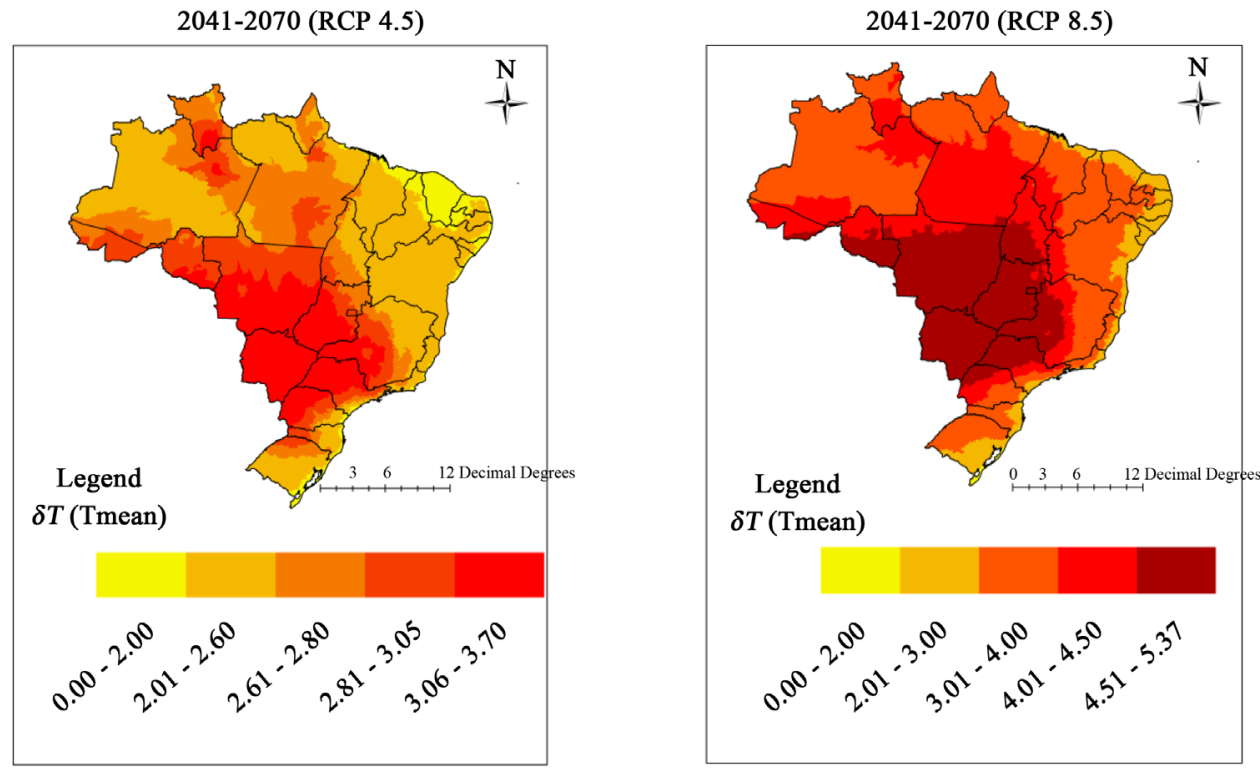

Figure 5. Municipalization of $\delta T\left({ }^{\circ} \mathrm{C}\right)$ in RCP 4.5 (left) and 8.5 (right) scenarios for 2041-2070.
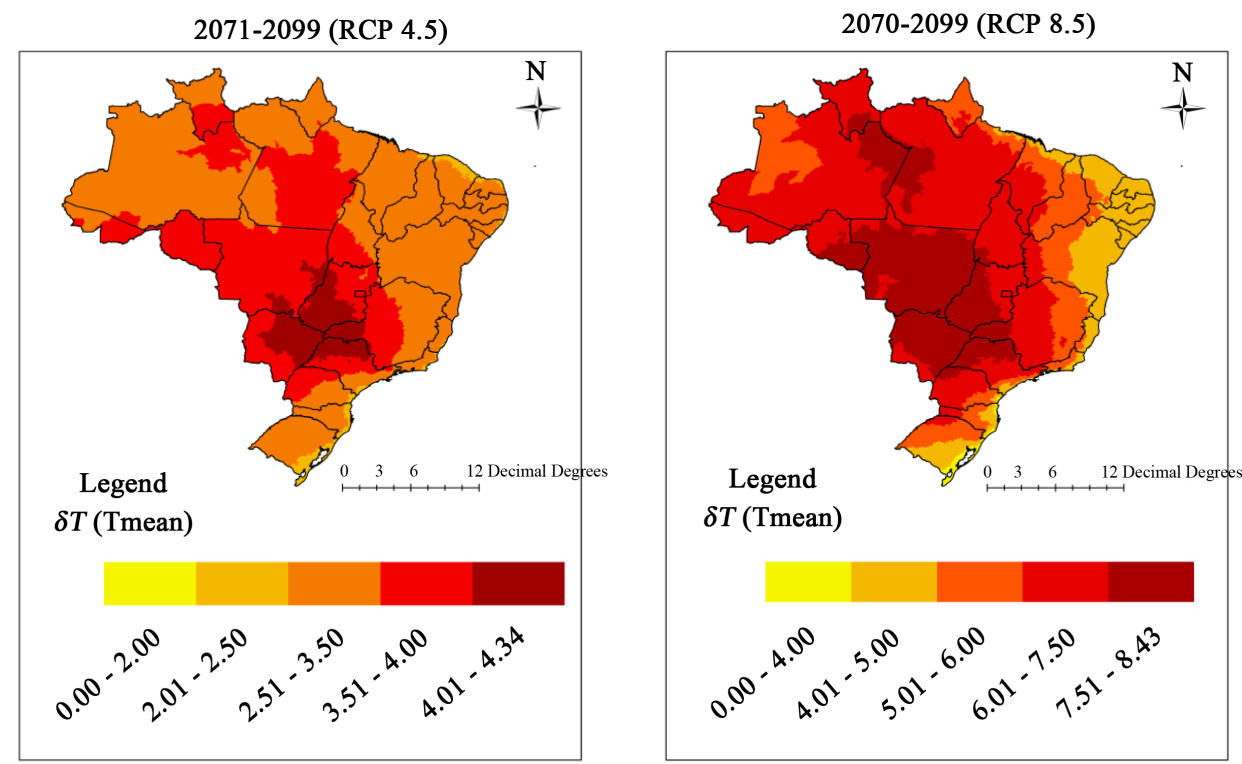

Figure 6. Municipalization of $\delta T\left({ }^{\circ} \mathrm{C}\right)$ in RCP 4.5 (left) and 8.5 (right) scenarios for 2071-2100.

Table 1. Summary of minimum, mean and maximum municipal temperature increase in average temperature in Brazil (in brackets the state code of the municipality is identified) using the Eta-Hadgem2-ES and MIROC5 models compared to the global mean of the CMIP5 multi-model ensemble in the two emission scenarios.

\begin{tabular}{ccccc}
\hline & World (CMIP5) & \multicolumn{2}{c}{ Brazil (Eta-HadGEM2-ES) Warming in 2071-2100 } \\
\cline { 2 - 5 } & Global Mean Warming $(2081-2100)^{*}$ & Minimum & Mean & Maximum \\
\hline RCP 4.5 & $1.1^{\circ} \mathrm{C}-2.6^{\circ} \mathrm{C}$ & $2^{\circ} \mathrm{C}(\mathrm{RS})$ & $3.18^{\circ} \mathrm{C}$ & $4.3^{\circ} \mathrm{C}(\mathrm{SP})$ \\
RCP 8.5 & $2.6^{\circ} \mathrm{C}-4.8^{\circ} \mathrm{C}$ & $3.2^{\circ} \mathrm{C}(\mathrm{RS})$ & $5.91^{\circ} \mathrm{C}$ & $8.4^{\circ} \mathrm{C}(\mathrm{AM})$ \\
$\begin{array}{c}\text { RCP 8.5 } \\
\text { (Eta-MIROC5) }\end{array}$ & $2.6^{\circ} \mathrm{C}-4.8^{\circ} \mathrm{C}$ & $1.9^{\circ} \mathrm{C}(\mathrm{RS})$ & $2.26^{\circ} \mathrm{C}$ & $5.4^{\circ} \mathrm{C}(\mathrm{MT})$ \\
\hline
\end{tabular}

"IPCC: Table SPM-2, in: Summary for Policymakers, in: IPCC AR5 WG1 2013, p. 21. 
change in future projections across Brazil. In the North region, especially in Western Amazon, there is a continuous increase in the number of days under a heatwave, both in the RCP 4.5 and 8.5 scenarios. In fact, in both scenarios it is possible to identify a hotspot of increasing heatwave conditions along the state boarder between Amazonas and Pará states, being more extensive during the last timeframe. Other geographical changes become clearer with the municipalised results in Figure 8.
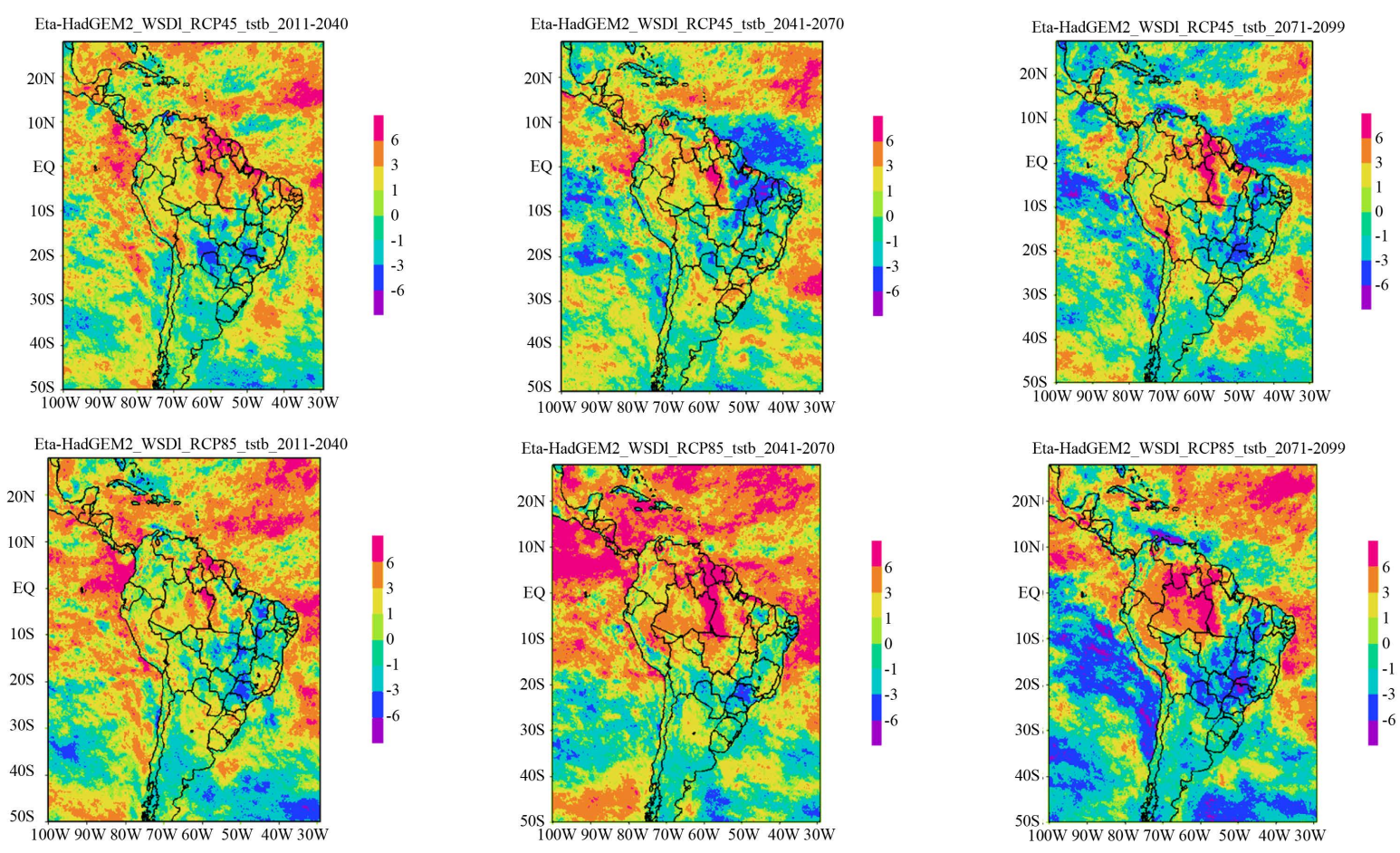

Figure 7. WSDI $\delta T$ model output according to the Eta-hadgem2-ES model in the timeframes and scenarios under analysis (left 2011-2040, center 2041-2070, right 2071-2099, above RCP 4.5 and below RCP 8.5).

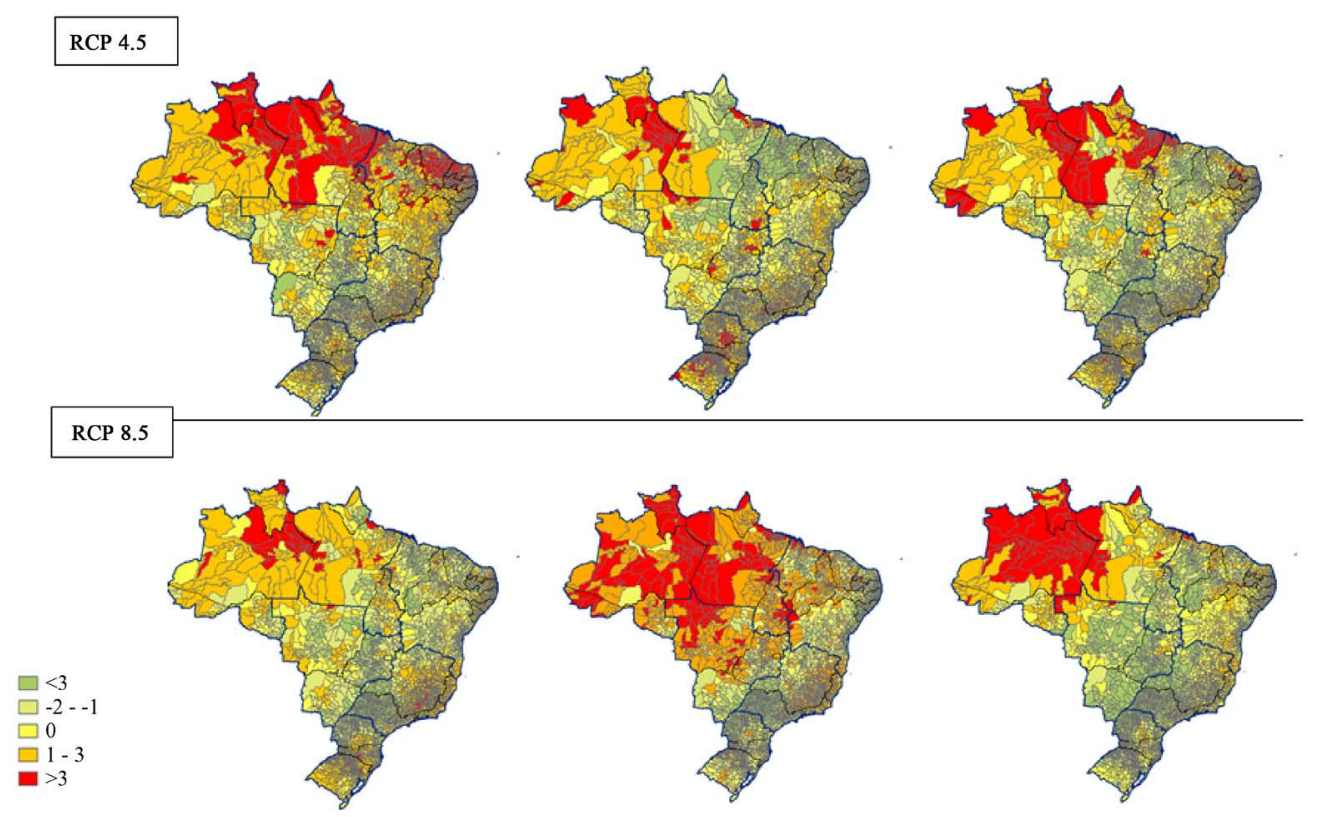

Figure 8. Municipalisation results of the WSDI $\delta T$ results shown in Figure 7 for 2011-2040 (left), 2041-2070 (centre) and 2071-2100 (right) in two emission scenarios (RCP 4.5 and RCP 8.5). 


\section{Discussion}

Heat waves are a major extreme weather factor that have an impact on human health, where climate change poses an increasing risk of cardiovascular and respiratory diseases (IPCC, 2014). Climate and land-surface changes have been responsible for an aggravation of recent heatwaves [19].

The WSDI shows a surprising decrease in the number of heatwaves in the RCP 8.5 scenario across large parts of Brazil, despite major increases in mean annual temperature. We hypothesise that this arises because of large-scale drying. In regions with seasonal or occasional soil moisture heat-waves are associated with unusually dry periods and reduced evaporative cooling of the surface [19]. However, in regions which are permanently dry this mechanism of generating unusually hot "heat-wave" periods does not exist, because the surface is always dry. This is probably the reason why in the South and Southeast regions there seems to be a reduction on the number of heatwave days, despite the intense warming in mean temperatures (see Figures 4-6) and there being some municipalities where there is a change of above +3 days/year, as early as the mid-century $(4.5$ scenario in Figure 8).

The main advantage of municipalizing climate predictions from gridded model outputs is enhancing integrated analysis between climate and non-climatic variables such as socioeconomic, environmental and health data, that invariably are organized under an administrative grid and in which the municipality is one of the finest in resolution.

This municipalisation technique was firstly applied for a climate change health risk and impact assessment also under the Brazilian National Communication to the UNFCCC. Details of such methodologies and findings can be found in [9] [10] [20].

\subsection{Example of a Joint Climate-Socioeconomic Analysis}

Increases in mean temperatures can have different exposures and subsequent implications for human and ecosystems health, environmental services and human assets. The IPCC defines Exposure as the places where any of these can be adversely affected [15] by significant climate variations.

Hence, in order to assess levels of exposure, it is essential to identify which assets, services and people can be affected and especially where, why and how this varies across space.

In this section, a spatially integrated analysis was conducted combining the mean $\delta T$ results from the RCP4.5 and 8.5 emission scenarios with municipal GDP per capita from the 2010 census in order to estimate the exposure of people and their economic resources to increased mean temperature across Brazil. While it is acknowledged that it has its shortcomings in for example, measuring real welfare and in taking into account distribution of wealth, GDP per capita is nonetheless considered a key component of human welfare as an estimator of the overall available financial resources and services available for a given population [21].

Figure 9 describes a quartile distribution of GDP per capita across Brazil, showing a clear concentration of wealthier municipalities in the South, Southeast and Centre-West regions and poorer ones in the North and Northeast. There are some positive exceptions for the states of Rondonia and Tocantins in the North region and negative in the eastern side of Minas Gerais.

\subsection{GDP per Capita and Municipal Temperature Increase Analysis}

A quartile matrix of temperature increase $(\delta T)$ and GDP per capita was created to enable the identification and spatial combination of low and high values of both indicators. Figure 10 shows the matrix with number classifications where the first digit defines the quartile of $\delta T$ and the second digit the GDP per capita quartile. Hence, for example 41 stands for $4-4^{\text {th }}$ quartile of $\delta T$; and $1-1^{\text {st }}$ quartile of GDP per capita.

Exposure per se is mostly controlled by $\delta T$, however its adverse effects on people are very much related with other socioeconomic [6] factors which GDP per capita is a good proxy of. The amount of available resources that create conditions of resilience to exposed populations and places as well as their adaptive capacity is an essential element to assess levels of exposure. Hence, the colours in the matrix represent a gradient of intensity of exposure where low GDP per capita aggravates exposure to higher warming. Ultimately, the matrix allows visualising places where warming may have stronger impacts but also further understand the implications of spatially unequal distributions of wealth under different levels of warming exposure from two different future global emission scenarios. 


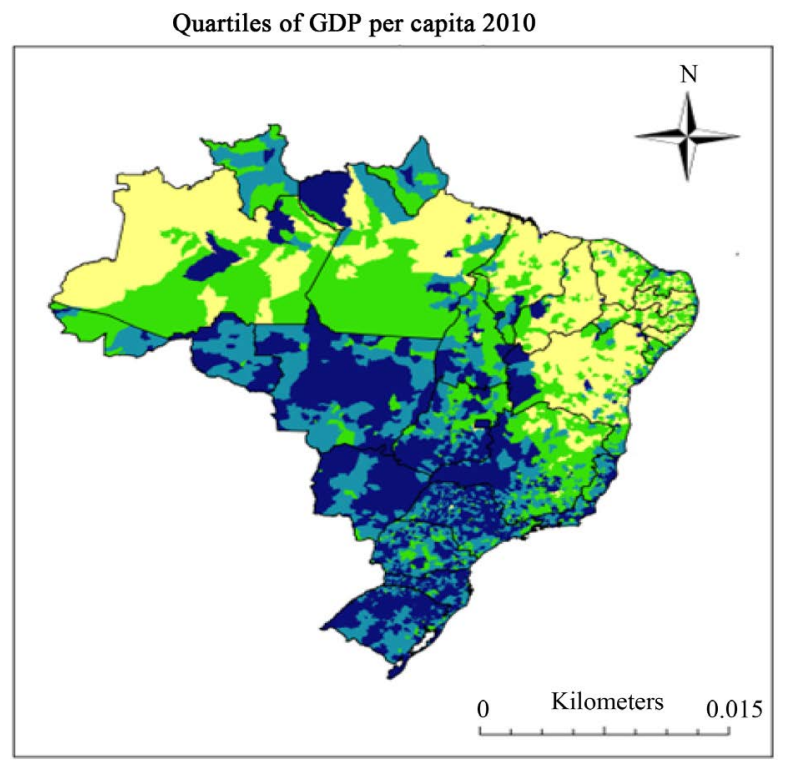

GDP per capita quartiles (2010)

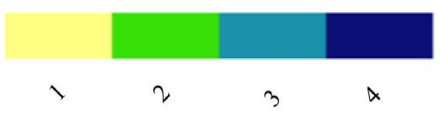

Figure 9. Quartiles of municipal GDP per capita.

RCP 8.5

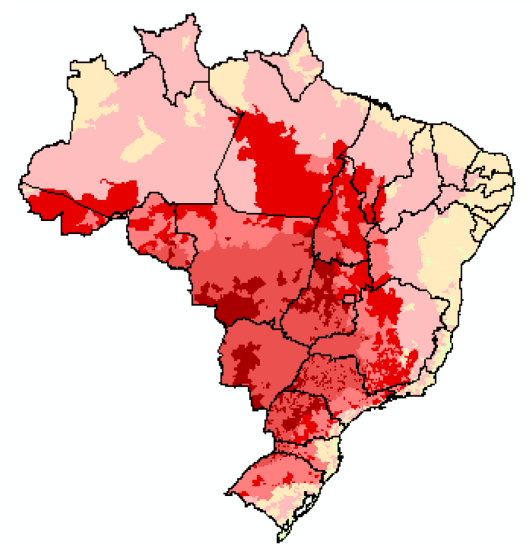

2011-2040

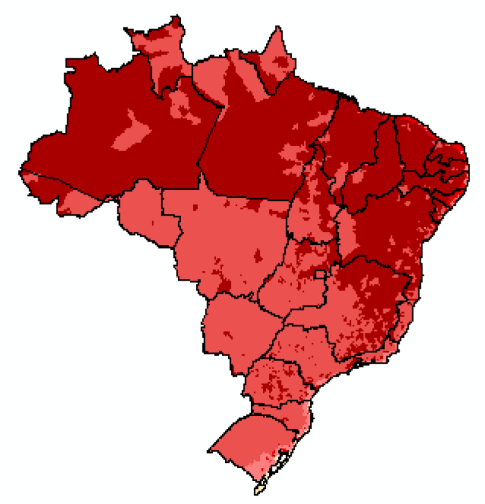

2041-2070

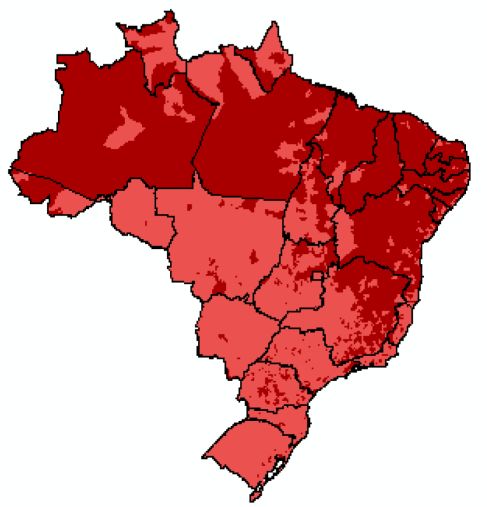

2071-2100

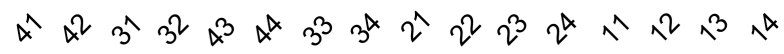

\begin{tabular}{|c|c|c|c|c|}
\hline & \multicolumn{4}{|c|}{ GDP-capita (Quartiles) } \\
\hline OT & $\mathrm{VL}$ & $\mathrm{L}$ & $\mathrm{H}$ & $\mathrm{VH}$ \\
\hline Q1 & 11 & 12 & 13 & 14 \\
\hline Q2 & 21 & 22 & 23 & 24 \\
\hline Q3 & 31 & 32 & 33 & 34 \\
\hline Q4 & 41 & 42 & 43 & 44 \\
\hline
\end{tabular}

Figure 10. Results for joint temperature increase $(\delta T)$ and GDPc in the RCP 8.5 and Quartile Matrix and colour bar. 
The results from this integration in Figure 11 in the RCP 4.5 scenario show that the more intense warming in the beginning of the century happens in the Centre-West, Southeast and South regions, which is where the wealthiest municipalities are located. However, by mid-century, most municipalities in the North region and the Northeast semi-arid (where the lowest levels of GDP per capita in the country are located) also reach the $3^{\text {rd }}$ and $4^{\text {th }}$ quartiles of warming.

In the RCP 8.5 scenario this trend is aggravated and anticipated. The main difference is that it is no longer the wealthiest municipalities having the top warming from the beginning of the century, but also many of the poorest in the North region which now have 3rd quartile warming, in comparison to 2nd and 1st quartile warming in the first time slice and in the RCP 4.5 scenario. The biggest change in this scenario however happens in the second time slice, when the end-of-the-century extreme warming from both scenarios is anticipated to the midcentury. This anticipation affects especially the most economically-prone municipalities which in the 4.5 scenario would only find such top temperature increases by the end of the century.

In conclusion, this exploratory integrated analysis of temperature increase and GDP per capita enabled a first identification of municipalities within the North and Northeast regions where, despite having a lesser warming rate, their risk from exposure to warming is considerably high due to their relatively lower wealth. The difference between scenarios also gives evidence that in RCP 8.5, economically vulnerable parts of the country will have less time to build resilience and adapt to climate change, as they are affected by the highest temperature increases earlier on the 21st century.

\section{RCP 4.5}
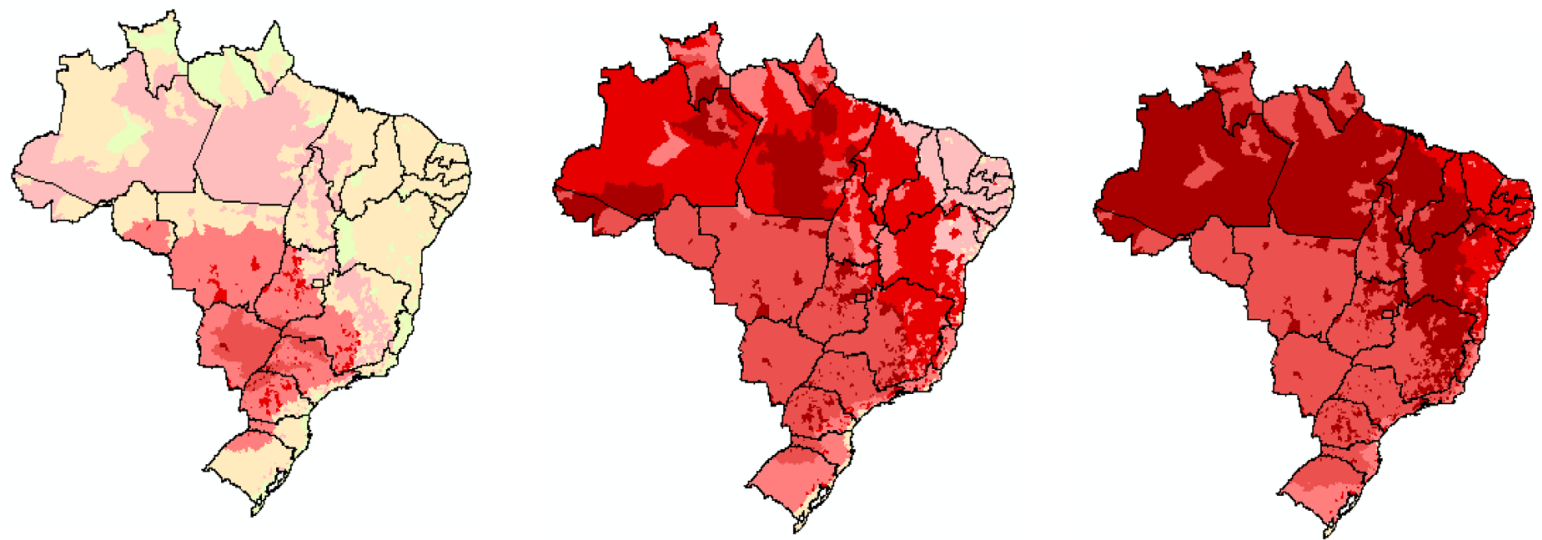

$$
\text { 2011-2040 }
$$

2041-2070

$2071-2100$

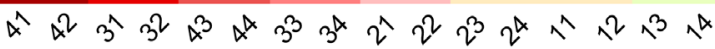

\begin{tabular}{|c|c|c|c|c|}
\hline & \multicolumn{4}{|c|}{ GDP-capita (Quartiles) } \\
\hline $\bar{O} T$ & $\mathrm{VL}$ & $\mathrm{L}$ & $\mathrm{H}$ & $\mathrm{VH}$ \\
\hline Q1 & 11 & 12 & 13 & 14 \\
\hline Q2 & 21 & 22 & 23 & 24 \\
\hline Q3 & 31 & 32 & 33 & 34 \\
\hline Q4 & 41 & 42 & 43 & 44 \\
\hline
\end{tabular}

Figure 11. Results for joint temperature increase ( $\delta T$ ) (from Very Low (VL) to Very High (VH)) and GDPc in the RCP 4.5 and Quartile Matrix and colour bar.

\section{Conclusions}

This article presents the application of a novel spatial methodology that allows an interpolation of gridded climate model predictions into a meaningful jurisdictional framework, in this case, to the Brazilian municipal network. This work is an important step to allow an integrated spatial analysis of climate and socioeconomic and health data as part of a larger effort to analyze the vulnerability and impacts of climate change to human health 
in Brazil under the country’s Third National Communication to the UNFCCC.

This technique was applied to the projected change in annual mean temperature and a widely-used heat-wave index (WSDI) allowing the identification and quantification of regional disparities between Brazilian cities of warming during the $21^{\text {st }}$ century under two different global emission scenarios. The results show a clear differential warming trend higher in the continental interior of the country comparing with coastland areas. The WSDI shows a spatially diverse and scenario dependent change except for the Amazon region where an increase in frequency of heatwaves days is continuous in both scenarios. The municipal analysis of heatwaves also enabled the identification of localized patterns of increased frequency of heatwaves days.

This paper also shows a practical application of this methodology exploring GDP per capita data and jointly analyzing spatial patterns of warming. The aim of this section is not to provide definite prognostics of Brazilian differential exposure to warming but rather to provide insight into the most vulnerable areas of Brazil. The results show that the regions with highest warming generally coincide with the higher GDPc municipalities of the country in the Centre-West, Southeast and South regions. However, important pockets of poorer municipalities are within these areas and, with lower resources, are more likely to suffer more negatively from steep increases in temperature.

Furthermore, it is important to note that the Centre-West region, where warming is the highest in Brazil, has only in the last 15 years achieved the top GDP quartiles, largely thanks to an increase of the agribusiness sector (namely into the Amazon forest region, through deforestation). With such increases in mean temperature, it is imperative to evaluate the economic implications of such extreme warming (even in a globally sustainable scenario) for the agribusiness sector in the region and the existence of potential climate thresholds at which the ecological viability of the current agribusiness model may be compromised and recent economic growth achieved may be reversed due to climate change. Furthermore, by mid-century, warming spreads into the North and the Northeast semi-arid, where the lowest levels of municipal GDP are located in Brazil.

\section{Acknowledgements}

This work would not have been possible to achieve without the support of Dr. Chou Sin Chan, coordinator of the Eta model development at CPTEC/INPE and her team (special thanks to Andre Lyra and Adan Silva) in providing the latest $20 \mathrm{kms}$ resolution Eta model runs. Similarly, the authors would like to thank the Third National Communication coordinating team, particularly Breno Teixeira and Dr. Jose Marengo, as well as the United Nations Programme for Development (UNDP), Rede Clima (FINEP 01.13.0353.00), and the Brazilian Ministry for Science and Technology for their financial support and encouragement to achieve these results within the short timeframe available. Important lessons from the PULSE-Brazil project (NERC NE/J016276/1 and FAPESP 2011/51843-2) were taken on understanding needs for climate information for policy applications and for that the authors are also thankful to this project and its funders. Finally, a heartfelt word of gratitude to colleagues and friends such as Guilherme Martins, Felipe Ferreira, Raphael Pousa and Lincoln Alves at CCST/INPE and Andreia Sobral and Jefferson Pereira at ENSP/Fiocruz who voluntarily made their time available to help with technical solutions and shed insightful light onto GrADS visualisation options for climate data as well as for spatial interpolation and ArcGIS scripting.

\section{References}

[1] Vaughan, C. and Dessai, S. (2014) Climate Services for Society: Origins, Institutional Arrangements, and Design Elements for an Evaluation Framework. Wiley Interdisciplinary Reviews-Climate Change, 5, 587-603. http://dx.doi.org/10.1002/wcc. 290

[2] Flato, G.M. (2011) Earth System Models: An Overview. Wiley Interdisciplinary Reviews-Climate Change, 2, $783-800$. http://dx.doi.org/10.1002/wcc.148

[3] Chou, S.C., Marengo, J.A., Lyra, A.A., Sueiro, G., Pesquero, J.F., Alves, L.M., Kay, G., Betts, R., Chagas, D.J., Gomes, J.L., Bustamante, J.F. and Tavares, P. (2012) Downscaling of South America Present Climate Driven by 4Member HadCM3 Runs. Climate Dynamics, 38, 635-653. http://dx.doi.org/10.1007/s00382-011-1002-8

[4] Pesquero, J.F., Chou, S.C., Nobre, C.A. and Marengo, J.A. (2010) Climate Downscaling over South America for 19611970 Using the Eta Model. Theoretical and Applied Climatology, 99, 75-93. http://dx.doi.org/10.1007/s00704-009-0123-z

[5] Chou, S.C., Lyra, A., Mourão, C., Dereczynski, C., Pilotto, I., Gomes, J., Bustamante, J., Tavares, P., Silva, A., Rodrigues, D., Campos, D., Chagas, D., Sueiro, G., Siqueira, G. and Nobre, P. (2014) Evaluation of the Eta Simulations 
Nested in Three Global Climate Models. American Journal of Climate Change, 3, 438-454.

http://dx.doi.org/10.4236/ajcc.2014.35039

[6] Adger, W.N. (2006) Vulnerability. Global Environmental Change, 16, 268-281.

http://dx.doi.org/10.1016/j.gloenvcha.2006.02.006

[7] Marengo, J., Aragao, L., Cox, P., Costa, D., Smith, L., Alves, L., Betts, R., Kaye, N., Hacon, S.S. and Reis, V. (2015) Impacts of Climate Extremes in Brazil: The Development of a Web Platform for Understanding. Bulletin of the American Meteorological Society (submitted).

[8] Aragão, L.E.O.C.A., Marengo, J.L., Cox, P., Costa, D., Smith, L., Betts, R., Kaye, N., et al. (2015) Climate Impacts on Ecosystems and Human-Health in Brazil Quantified Using a Web Platform for Decision-Making. Environmental Research Letters (submitted).

[9] Pinheiro, S.L.L.A., Hacon, S.S., Siqueira, A.S.P., Gonçalves, K.S., Costa, D. and Oliveira, A. (2015a) Health Vulnerability to Climate Change in Brazil: Mapping Composite Indexes Based on Principal Component Analysis. EcoHealth (submitted).

[10] Pinheiro, S.L.L.A., Hacon, S.S., Siqueira, A.S.P., Gonçalves, K.S., Costa, D. and Oliveira, A. (2015) Heat Waves and Health: Vulnerabilities, Risk and Impacts on Mortality Considering Climate Change Scenarios in Brazil. Weather and Climate Extremes, In Preparation.

[11] Nairn, J., Fawcett, R. and Ray, D. (2009) CAWCR Technical Report No. 071: Modelling and Understanding High Impact Weather. Proceedings of the Third CAWCR Modelling Workshop, Melbourne, 30 November-2 December 2009, 83-86.

[12] Perkins, S.E. and Alexander, L.V. (2013) On the Measurement of Heat Waves. Journal of Climate, 26, 4500-4517. http://dx.doi.org/10.1175/JCLI-D-12-00383.1

[13] Fischer, E.M. and Schär, C. (2010) Consistent Geographical Patterns of Changes in High-Impact European Heatwaves. Nature Geoscience, 3, 398-403. http://dx.doi.org/10.1038/ngeo866

[14] Meehl, G.A. and Tebaldi, C. (2004) More Intense, More Frequent, and Longer Lasting Heat Waves in the 21st Century. Science, 305, 994-997. http://dx.doi.org/10.1126/science.1098704

[15] Huth, R., Kyselý, J. and Pokorná, L. (2000) A GCM Simulation of Heat Waves, Dry Spells, and Their Relationships to Circulation. Climatic Change, 46, 29-60. http://dx.doi.org/10.1023/A:1005633925903

[16] Alexander, L.V. and Arblaster, J.M. (2009) Assessing Trends in Observed and Modelled Climate Extremes over Australia in Relation to Future Projections. International Journal of Climatology, 29, 417-435. http://dx.doi.org/10.1002/joc.1730

[17] Zhang, X., Alexander, L., Hegerl, G.C., Jones, P., Tank, A.K., Peterson, T.C., Trewin, B. and Zwiers, F.W. (2011) Indices for Monitoring Changes in Extremes Based on Daily Temperature and Precipitation Data. Wiley Interdisciplinary Reviews: Climate Change, 2, 851-870. http://dx.doi.org/10.1002/wcc.147

[18] Sillmann, J., Kharin, V.V., Zwiers, F.W., Zhang, X. and Bronaugh, D. (2013) Climate Extremes Indices in the CMIP5 Multi-Model Ensemble: Part 2. Future Climate Projections. Journal of Geophysical Research: Atmospheres, 118, 2473-2493. http://dx.doi.org/10.1002/jgrd.50188

[19] Fischer, E.M., Seneviratne, S.I., Lüthi, D. and Schär, C. (2007) Contribution of Land-Atmosphere Coupling to Recent European Summer Heat Waves. Geophysical Research Letters, 34, 1-6. http://dx.doi.org/10.1029/2006GL029068

[20] Oliveira, A., Hacon, S.S., Costa, D., Pinheiro, S., Pereira, C., et al. (2015) Impacto das projeções de temperatura ambiente na diarreia infantil no Brasil. Revista Pan Americana de Salud Publica (submitted).

[21] Oulton, N. (2012) Hooray for GDP! Centre for Economic Performance Occasional Papers, CEPOP30. Centre for Economic Performance, London School of Economics and Political Science, London. 